\title{
PENGGUNAAN MEDIA, BAHAN STEK, DAN ZAT PENGATUR TUMBUH TERHADAP KEBERHASILAN STEK MASOYI (Cryptocarya massoy (Oken) Kosterm)
}

\author{
The Use of Medias, Cutting Materials, and Plant Growth Regulator Towards The Success \\ of Masoyi (Cryptocarya massoy (Oken) Kosterm) Cutting \\ Darwo dan/and Irma Yeny \\ Pusat Penelitian dan Pengembangan Hutan \\ Jl. Gunung Batu No. 5 Po Box 165 Bogor, Jawa Barat, Indonesia Telp. 0251-8633234; Fax 0251-8638111 \\ E-mail: darwop3h@gmail.com; irmayeny.kemenhut@yahoo.com
}

Tanggal diterima: 27 April 2017; Tanggal direvisi: 9 April 2018; Tanggal disetujui: 25 Mei 2018

\begin{abstract}
Masoyi (Cryptocarya massoy) is one of the high economic value, non-wood forest products endemic to Papua. Development of masoyi plants currently are constrained by meeting the needs for quality seeds in a large quantity on time. Therefore, vegetative propagation become one of the solutions for this problem. The aim of this study was to get the best media, cutting materials, and doses of growth regulators for vegetative propagation of masoyi. Completely randomized factorial design was used. The first factor was the media of cuttings (soil+sand $(2: 1, v / v)$, coconut fiber+husk $(2: 1, v / v)$, and sand media). The second factor was cutting materials derived from 1 year old seedlings (the upper shoots and the down shoots). The third factor was the concentration of growth regulators (0; 500; and 1,000 ppm of NAA). The root percentage was influenced by media, the shoots, and growth regulator NAA. Root length was influenced by media as a single factor and the interaction between media and the shoots. The number of leaves was influenced by the media, while the number of roots was not influenced by each single factor and their interactions. Media was a critical factor for the success of masoyi cuttings. Thus, the combination of soil+sand $(2: 1, v / v)$ media with the upper shoots is a recommended treatment for masoyi shoot cuttings, where the combination is not influenced by the growth regulator NAA.
\end{abstract}

Keywords: Cryptocarya massoy, growth regulator, media, shoot cuttings

\begin{abstract}
ABSTRAK
Masoyi (Cryptocarya massoy) merupakan salah satu jenis tanaman penghasil hasil hutan bukan kayu (HHBK) endemik Papua bernilai ekonomi tinggi. Upaya pengembangan tanaman masoyi saat ini terkendala oleh sulitnya memenuhi kebutuhan bibit dalam jumlah banyak dan berkualitas. Untuk itu, perbanyakan secara vegetatif menjadi salah satu solusi permasalahan pemenuhan bibit. Penelitian bertujuan mendapatkan media tanam, bahan stek, dan dosis zat pengatur tumbuh NAA yang tepat untuk perbanyakan masoyi dengan cara stek. Penelitian menggunakan bibit berumur 1 tahun dengan Rancangan Acak Lengkap Faktorial. Faktor pertama adalah media tanam stek (tanah+pasir $(2: 1, \mathrm{v} / \mathrm{v})$, serbuk sabut kelapa+ sekam (2:1, v/v), dan media pasir). Faktor kedua adalah bahan stek (bagian pucuk atas dan bagian pucuk bawah). Faktor ketiga adalah konsentrasi zat pengatur tumbuh (0 ppm, NAA 500 ppm, dan NAA 1.000 ppm). Hasil penelitian menunjukkan bahwa persen berakar dipengaruhi oleh faktor tunggal media tanam, bagian stek dan zat pengatur tumbuh NAA. Panjang akar dipengaruhi oleh faktor tunggal media tanam dan interaksi antara media dengan bagian stek. Jumlah daun dipengaruhi faktor media tanam, sedangkan jumlah akar tidak dipengaruhi masing-masing faktor tunggal dan interaksinya. Faktor media merupakan faktor penentu keberhasilan stek masoyi. Dengan demikian, kombinasi media tanah+pasir $(2: 1$, v/v) dengan bagian pucuk atas merupakan perlakuan yang direkomendasikan untuk stek masoyi, dan kombinasi perlakuan tersebut tidak dipengaruhi oleh zat pengatur tumbuh NAA.
\end{abstract}

Kata Kunci : Cryptocarya massoy, media, stek pucuk, zat pengatur tumbuh 


\section{PENDAHULUAN}

\section{Cryptocarya massoy (Oken)}

Kosterm memiliki sinonim dengan Cinnamomum massoy Oken, Cryptocarya aromatica (Becc) Kosterm, Cryptocaria novoguineensis Teschner dan Massoaia aromatica Becc) dan termasuk famili Lauraceae. Jenis ini dikenal dengan nama aikor atau aikori, Masoyi (Papua), Mangsoi (Sunda), Masogi (Jawa) dan Masoji (Madura) dan Masohi (Badan Standarisasi Nasional, 2013). Jenis C. massoy dikenal dengan nama masoyi, yang umum digunakan oleh pedagang/ pengumpul di Papua. Tanaman masoyi merupakan penghasil minyak atsiri dengan senyawa aktif lactone. Masoialactone dan $\delta$-decalactone ditemukan dalam jumlah banyak pada kulit batang. Minyak masoyi diperoleh melalui ekstraksi kulit dengan rendemen mencapai lebih dari 2\% (Suminar, Arifin, \& Kemala, 2015). Senyawa ini secara tradisional dimanfaatkan sebagai bahan makanan dan jamu, obat sakit perut dan cacingan, penambah rasa dan aroma makanan (flavor), kosmetik, dan obat penenang (Rostiwati \& Efendi, 2013). Di Eropa minyak masoyi digunakan sebagai flavor agar makanan memiliki aroma seperti kelapa. Selain itu, negara Amerika memanfaatkan minyak masoyi sebagai flavor es krim (Suminar et al., 2015).

Eksploitasi masoyi telah dilakukan sejak tahun 1980-an bersamaan dengan menjamurnya unit Hak Pengelolaan Hutan (HPH) di Indonesia. Sampai saat ini data produksi masoyi tidak pernah tercatat dengan baik, sehingga potensi riil di alam sulit diketahui. Kebutuhan minyak masoyi dunia $100 \%$ diekstraksi dari kulit batang yang diambil dari pohon-pohon di Papua dan Papua New Guinea (PNG) dengan nilai produksi Indonesia mencapai 8-12 ribu ton/tahun (Suminar et al., 2015).

Kondisi ini menunjukkan keberadaan masoyi sangat bernilai, namun keter- sediaannya di alam sudah semakin berkurang. Beberapa pemegang izin Hutan Tanaman Rakyat (HTR) sudah tertarik untuk mengembangkan masoyi dalam skema hutan tanaman. Namun, sampai saat ini masih terkendala dalam teknik budidaya, yaitu (1) penyediaan bibit yang bermutu dalam jumlah yang cukup dan tersedia tepat waktu serta (2) kemampuan adaptasi masoyi untuk tumbuh di luar tempat tumbuh alaminya. Upaya penyediaan bibit secara generatif terkendala oleh sulitnya memperoleh biji masoyi sebagai akibat semakin berkurangnya pohon penghasil sumber benih di alam. Selain itu benih masoyi bersifat recalsitran, sehingga tidak dapat disimpan dalam waktu lama.

Untuk mengatasi kendala penyediaan bibit, stek merupakan salah satu teknik perbanyakan secara vegetatif yang tergolong mudah, sederhana, ekonomis serta dapat memproduksi bibit dalam jumlah banyak (Subiakto, 2009). Stek memungkinkan dilakukan sebagai salah satu metode perbanyakan vegetatif dari jenisjenis yang sulit diperbanyak secara generatif dan mempunyai keunggulan dimana seluruh karakter yang dimiliki pohon induk akan diwariskan kepada keturunannya.

Keberhasilan stek dipengaruhi oleh interaksi faktor genetik dan faktor lingkungan (Danu, Subiakto, \& Putri, 2011). Faktor genetik meliputi kandungan cadangan makanan dalam jaringan stek, ketersediaan air, umur tanaman (pohon induk) dan hormon endogen dalam jaringan stek. Faktor lingkungan juga memengaruhi, antara lain media perakaran, kelembaban, suhu, interaksi cahaya, dan teknik penyetekan.

Pemahaman aspek fisiologis selama pembentukan akar dan tunas serta penguasaan teknologi manipulasi lingkungan adalah kunci keberhasilan stek (Subiakto, 2009). Parameter fisiologis yang penting dicermati adalah intensitas cahaya, tegangan air daun dan temperatur 
daun (Subiakto, 2009). Dari parameter fisiologis serta manipulasi lingkungan telah diperoleh teknik perbanyakan sistem stek dengan sungkup propagasi yang dinamakan "KOFFCO system" akronim dari Komatsu-FORDA Fog Cooling System. Sistem KOFFCO telah digunakan memproduksi bibit jenis dipterokarpa dan jenis pohon indigenous lainnya. Penelitian ini bertujuan untuk mengetahui keberhasilan perbanyakan stek masoyi menggunakan sistem KOFFCO dengan perlakuan media, bahan stek dan dosis zat pengatur tumbuh NAA.

\section{METODOLOGI}

\section{A. Lokasi dan Waktu Penelitian}

Penelitian dilakukan di rumah kaca Pusat Penelitian dan Pengembangan Hutan Bogor. Penelitian berlangsung pada bulan Mei sampai November 2016. Bahan stek yang digunakan adalah anakan masoyi yang berasal dari cabutan alam yang diperoleh dari Kabupaten Fakfak, Provinsi Papua Barat. Bibit asal cabutan dipelihara sampai berumur 1 tahun, selanjutnya dijadikan bahan indukan untuk pembuatan stek. Bahan stek berupa stek pucuk bagian atas dan stek pucuk bagian bawah. Bahan stek pucuk diambil bagian juvenil yaitu 2 ruas daun atau 3 nodul bagian atas dan bahan stek pucuk bagian bawah diambil 3 nodul berikutnya setelah bagian pucuk atas yang masih memiliki daun. Bahan untuk media adalah tanah, pasir, arang sekam dan serbuk sabut kelapa. Zat pengatur tumbuh yang digunakan adalah NAA (Napthalene Acetic Acid).

\section{B. Metode}

\section{Prosedur kerja}

Pembuatan stek menggunakan metode sistem KOFFCO (Istomo, Subiakto, \& Ragmadianto, 2014). Pucuk diambil dari bibit yang berumur 1 tahun dan dilakukan pada pagi hari antara pukul 07.00-10.00. Pada bagian pangkal disayat dengan kemiringan $45^{\circ}$. Untuk mengurangi penguapan, masing-masing bahan stek disisakan 2-3 helai daun dan setiap helai dipotong separuhnya. Bagian pangkal bahan stek selanjutnya direndam di dalam larutan hormon NAA sesuai dosis perlakuan selama 15 menit. Bahan stek yang telah diberi perlakuan hormon ditanam pada beberapa perlakuan media yang sudah disterilkan dan disiram sampai jenuh, lalu disungkup plastik. Selanjutnya sungkup diletakkan pada rumah kaca yang dilengkapi dengan sistem pendingin (cooling system) atau ruang KOFFCO (Komatsu-FORDA Fog Cooling System). Sistem KOFFCO memiliki suhu $<30^{\circ} \mathrm{C}$, kelembaban $>95 \%$, dan intensitas cahaya $<20.000$ lux. Pemeliharaan stek dilakukan dengan penyiraman dan, pembersihan daun yang rontok agar tidak menimbulkan penyakit. Jika suhu melebihi $30^{\circ} \mathrm{C}$ dan kelembaban $<90 \%$, maka diberikan fogging untuk menstabilkan suhu dan kelembaban. Jika intensitas cahaya tinggi, maka dilakukan penutupan sungkup dengan shading net.

\section{Rancangan percobaan}

Penelitian menggunakan Rancangan Acak Lengkap (RAL) pola Faktorial dengan 3 faktor. Faktor pertama berupa media stek (M) yang terdiri dari 3 taraf, yaitu M1 = campuran media tanah+pasir $(2: 1, \mathrm{v} / \mathrm{v}), \mathrm{M} 2$ = campuran media serbuk sabut kelapa+sekam $(2: 1$, v/v), dan M3 = media pasir. Faktor kedua berupa bahan stek (B) dengan 2 taraf, yaitu B1 = stek pucuk bagian atas, dan B2 = stek pucuk bagian bawah. Faktor ketiga adalah konsetrasi zat pengatur tumbuh NAA $(\mathrm{H})$ terdiri dari 3 taraf $(\mathrm{H} 0=0 \mathrm{ppm}, \mathrm{H} 1=500$ ppm, dan H2 = 1.000 ppm). Setiap kombinasi perlakuan diulang tiga kali dan setiap unit percobaan terdiri dari 10 stek. 


\section{Pengamatan parameter pertum- buhan stek}

Parameter yang diamati meliputi: persen berakar, panjang akar, jumlah akar dan jumlah daun. Pengamatan dilakukan pada umur stek 16 minggu (4 bulan) dengan membongkar seluruh tanaman pada masing-masing perlakuan di setiap ulangan. Cara mengukur masing-masing parameter sebagai berikut (Istomo, Subiakto, \& Ragmadianto, 2014):

a. Persen berakar $=\frac{\text { ISAA }}{\text { JSA }} \times 100 \%$

dimana JSAA = Jumlah stek berakar pada akhir pengamatan, JSA = Jumlah stek awal pengamatan.

b. Panjang akar stek. Pengukuran panjang akar stek dilakukan dengan mengukur panjang akar dimulai dari titik munculnya akar sampai akar terujung.

c. Jumlah akar. Pengukuran jumlah akar stek dilakukan dengan menghitung banyaknya kemunculan akar adventif.

d. Jumlah daun. Pengukuran jumlah daun stek dilakukan dengan menghitung jumlah daun baru.

\section{Analisis media stek}

Analisis media stek dilakukan di laboratorium tanah SEAMEO-BIOTROP meliputi: kerapatan lindak (bulk density), kesarangan ruang pori total (porositas), kadar air pada kapasitas lapang, kadar air pada titik layu permanen, kadar air pori drainase cepat, pori drainase, dan jumlah air tersedia. Bulk density merupakan nilai berat kering tanah dibagi volume $(\mathrm{g} / \mathrm{cc})$. Pengeringan tanah dilakukan dengan menggunakan gravimetri pada suhu (105 $\pm 3)^{\circ} \mathrm{C}$ selama 24 jam. Sedangkan ruang pori total media stek dihitung dengan menggunakan rumus sebagai berikut:

Ruang pori total $=\frac{(2,65-\text { Bulk Density })}{2,65} \times 100 \%$

Kadar air media diukur dengan menggunakan alat Pressure Plate
Apparatus pada tekanan $\mathrm{pF}$ (log tinggi air) 1, pF 2, pF 2,54 (kapasitas lapang), dan $\mathrm{pF}$ 4,20 (titik layu permanen). Air tersedia dalam media (\% volume) merupakan hasil perhitungan dari kadar air media pada kapasitas lapang dikurangi dengan kadar air media pada titik layu permanen. Pori drainase cepat (\% volume) adalah hasil perhitungan dari ruang pori total dikurangi dengan kadar air media pada $\mathrm{pF} 2,00$. Pori drainase lambat merupakan hasil perhitungan dari kadarair media pada $\mathrm{pF}$ 2,00 dikurangi dengan kadar air media pada kapasitas lapang (pF 2,54) (Putri \& Danu, 2014).

\section{Analisis data}

Data yang diamati terdiri dari persen berakar stek, panjang akar stek, jumlah akar dan jumlah daun. Data hasil pengukuran selanjutnya dianalisis keragaman dengan menggunakan uji-F. Apabila terjadi perbedaan yang signifikan, maka dilakukan uji jarak berganda Duncan.

\section{HASIL DAN PEMBAHASAN}

\section{A. Hasil}

\section{Pertumbuhan stek masoyi}

Pohon masoyi dapat diperbanyak secara vegetatif yaitu dengan teknik stek. Stek masoyi mulai mengeluarkan akar pada umur 10 minggu. Hasil analisis ragam menunjukkan bahwa faktor tunggal media berpengaruh sangat nyata terhadap persen berakar, panjang akar, dan jumlah daun. Faktor tunggal bahan stek dan faktor zat pengatur tumbuh NAA berpengaruh nyata terhadap persen berakar. Pengaruh interaksi yang signifikan terjadi antara media dan bahan stek terhadap panjang akar. Parameter jumlah akar tidak dipengaruhi oleh semua komponen sumber keragaman.

Hasil uji lanjut menunjukkan bahwa media tanah+pasir $(2: 1, \quad \mathrm{v} / \mathrm{v})$ memiliki persen berakar, panjang akar, 
dan jumlah daun tertinggi $(71,67 \% ; 9,3$ $\mathrm{cm}$; dan 2 daun) sedangkan pada parameter jumlah akar ketiga media tidak berbeda. Bahan stek berpengaruh secara signifikan terhadap persen berakar, dan stek pucuk bagian atas menghasilkan persen berakar paling tinggi $(53,33 \%)$. Tanpa pemberian zat pengatur tumbuh NAA menunjukkan persen berakar $56,11 \%$ yang tidak berbeda nyata dengan pemberian NAA 500 ppm dan 1.000 ppm. Pada semua parameter yaitu persen berakar, panjang akar, jumlah akar, dan jumlah daun menunjukkan tidak ada perbedaan antara kontrol dengan dosis $500 \mathrm{ppm}$ dan $1.000 \mathrm{ppm}$. Kondisi ini menunjukkan bahwa stek masoyi dapat ditumbuhkan tanpa diberi hormon NAA (Tabel 2).

Terjadi interaksi yang signifikan antara faktor media dan faktor bahan stek terhadap panjang akar stek. Pada stek pucuk bagian atas maupun stek pucuk bagian bawah, media tanah+pasir (2:1, $\mathrm{v} / \mathrm{v})$ merupakan media yang terbaik untuk perkembangan panjang stek masoyi dibandingkan dengan media lain yang telah diujikan. Terhadap perkembangan panjang akan ternyata media serbuk sabut kelapa+sekam $(2: 1, \mathrm{v} / \mathrm{v})$ dengan media pasir tidak berbeda nyata, tetapi kedua media tersebut berbeda signifikan dengan media tanah+pasir $(2: 1, \mathrm{v} / \mathrm{v})$. Pada media tanah+pasir $(2: 1, \mathrm{v} / \mathrm{v})$, stek pucuk bagian atas menunjukkan pertumbuhan yang lebih baik daripada stek pucuk bagian bawah. Dengan demikian, bahan stek dan media perakaran yang terbaik untuk pertumbuhan akar stek masoyi adalah stek pucuk dengan media tanah+pasir (2:1, v/v) (Tabel 3).

Hasil penelitian ini menunjukkan bahwa perlakuan stek pucuk bagian atas dengan media tanah+pasir $(2: 1, \mathrm{v} / \mathrm{v})$ menghasilkan persen berakar, panjang akar, dan jumlah daun stek yang tertinggi pada stek masoyi (Tabel 2 dan Tabel 3).

\section{Sifat fisik media stek}

Sampel media untuk pengujian sifat fisik diambil dari media tanam steril yang belum digunakan. Hasil sifat fisik media stek yang dilakukan di Laboratorium BIOTROP disajikan pada Tabel 4.

Tabel (Table) 1. Pengaruh perlakuan media stek, bahan stek, dan dosis NAA terhadap parameter pertumbuhan stek $C$. massoy umur 16 minggu (The effects of cutting medias, cutting materials, and concentrations of NAA on growth parameters of $\underline{\mathrm{C}}$. massoy cutting at 16 weeks old)

\begin{tabular}{|c|c|c|c|c|}
\hline Sumber keragaman (Source of variance) & $\begin{array}{c}\text { Persen } \\
\text { berakar } \\
\text { (Rooting } \\
\text { Percentage) }\end{array}$ & $\begin{array}{l}\text { Panjang akar } \\
\text { (Root length) }\end{array}$ & $\begin{array}{c}\text { Jumlah akar } \\
\text { (Number of } \\
\text { roots })\end{array}$ & $\begin{array}{c}\text { Jumlah daun } \\
\text { (Number of } \\
\text { leaves) }\end{array}$ \\
\hline Media stek (Cutting medias) (M) & $* *$ & $* *$ & tn & $* *$ \\
\hline Bahan stek(Cutting materials) (B) & $*$ & tn & tn & tn \\
\hline Konsentasi zat pengatur tumbuh NAA & & & & \\
\hline (Concentrations of growth regular NAA) $(\mathrm{H})$ & $*$ & tn & $\operatorname{tn}$ & $\operatorname{tn}$ \\
\hline Interaksi (Interaction) M x B & $\operatorname{tn}$ & $* *$ & $\operatorname{tn}$ & $\operatorname{tn}$ \\
\hline Interaksi (Interaction) $\mathrm{M} \times \mathrm{H}$ & th & tn & $\operatorname{tn}$ & tn \\
\hline Interaksi (Interaction) $\mathrm{B} \times \mathrm{H}$ & $\operatorname{tn}$ & $\operatorname{tn}$ & tn & $\operatorname{tn}$ \\
\hline Interaksi (Interaction) M x B x H & tn & $\operatorname{tn}$ & tn & $\operatorname{tn}$ \\
\hline $\begin{aligned} \operatorname{arks)}: \operatorname{tn} & =\text { Tidak nyata taraf } \\
* & =\text { Nyata pada taraf } \\
* * & =\text { Sangat nyata tara }\end{aligned}$ & $\begin{array}{l}, 05 \text { (Not si } \\
05 \text { (Signific } \\
0,01 \text { (High }\end{array}$ & $\begin{array}{l}\text { ficant at } 0.051 \\
\text { t at } 0.05 \text { level } \\
\text { nificance at } 0 .\end{array}$ & $\begin{array}{l}\text { (level) } \\
\text { level) }\end{array}$ & \\
\hline
\end{tabular}


Tabel (Table) 2. Hasil uji beda pada masing-masing faktor media stek, bagian stek dan konsentrasi zat pengatur tumbuh NAA terhadap parameter pertumbuhan stek C. massoy umur 16 minggu (Analysis of the differences between the cutting medias, cutting materials, and concentrations of growth regulator NAA on growth parameters of $\underline{\mathrm{C}}$. massoy cutting at 16 weeks old)

\begin{tabular}{|c|c|c|c|c|}
\hline Parameter (Parameters) & $\begin{array}{c}\text { Persen berakar } \\
\text { (Rootingpercentage) } \\
(\%)\end{array}$ & $\begin{array}{l}\text { Panjang akar } \\
\text { (Root length) } \\
\quad(\mathrm{cm})\end{array}$ & $\begin{array}{c}\text { Jumlah akar } \\
\text { (Number of roots) } \\
\text { (Helai/Strands) }\end{array}$ & $\begin{array}{l}\text { Jumlah daun } \\
\text { (Number of } \\
\quad \text { leaves }) \\
\text { Helai (Strands) }\end{array}$ \\
\hline $\begin{array}{l}\text { 1. Media stek (Cutting medias } \\
\text { a. Tanah+pasir (Soil+sand) } \\
(2: 1, \mathrm{v} / \mathrm{v})\end{array}$ & $71,67 \mathrm{a}$ & $9,30 \mathrm{a}$ & $2,14 \mathrm{a}$ & 1,99 a \\
\hline $\begin{array}{l}\text { b. Sebuk sabut kelapa+ } \\
\text { sekam (Cocopet+ husk) } \\
(2: 1, \mathrm{v} / \mathrm{v})\end{array}$ & $35,01 \mathrm{~b}$ & $4,46 \mathrm{~b}$ & $2,13 \mathrm{a}$ & $0,23 \mathrm{~b}$ \\
\hline c. Pasir (Sand) & $36,67 \mathrm{~b}$ & $5,19 \mathrm{~b}$ & $1,69 \mathrm{a}$ & $0,95 \mathrm{~b}$ \\
\hline \multicolumn{5}{|l|}{ 2. Bahan stek (Cutting materials) } \\
\hline $\begin{array}{l}\text { a. Stek pucuk bagian atas } \\
\text { (Upper shoot cutting) }\end{array}$ & 53,33 a & $6,78 \mathrm{a}$ & $2,18 \mathrm{a}$ & $1,11 \mathrm{a}$ \\
\hline $\begin{array}{l}\text { b. Stek pucuk bagian bawah } \\
\text { (Down shoot cutting) }\end{array}$ & $42,22 \mathrm{~b}$ & $5,91 \mathrm{a}$ & $1,78 \mathrm{a}$ & $1,00 \mathrm{a}$ \\
\hline \multicolumn{5}{|l|}{$\begin{array}{l}\text { 3. Konsentrasi NAA } \\
\text { (Concentrations of NAA): }\end{array}$} \\
\hline a. $\quad 0 \mathrm{ppm}$ & $56,11 \mathrm{a}$ & $6,66 \mathrm{a}$ & $2,11 \mathrm{a}$ & $1,19 \mathrm{a}$ \\
\hline b. $500 \mathrm{ppm}$ & $37,22 \mathrm{~b}$ & $6,20 \mathrm{a}$ & $1,98 \mathrm{a}$ & $1,05 \mathrm{a}$ \\
\hline c. $1.000 \mathrm{ppm}$ & $50,00 \mathrm{ab}$ & $6,17 \mathrm{a}$ & $1,85 \mathrm{a}$ & $0,94 \mathrm{a}$ \\
\hline
\end{tabular}

Keterangan (Remark): Angka yang diikuti dengan huruf yang sama pada kolom yang sama tidak berbeda nyata pada taraf uji 5\% (DMRT) (Values in rows followed by the same letter in the same column are not significantly different at level of 5\% base on Duncan Multiple Range Test)

Tabel (Table) 3. Interaksi antara media stek dengan bahan stek terhadap panjang akar stek C. Massoy pada umur 16 minggu (Interactions between cutting medias and cutting materials on the length of $\underline{\mathrm{C}}$. massoy cutting rootsat 16 weeks old)

\begin{tabular}{|c|c|c|}
\hline \multirow[b]{2}{*}{ Media stek (Cutting medias) } & \multicolumn{2}{|c|}{ Panjang akar (Root length) $(\mathrm{cm})$} \\
\hline & $\begin{array}{c}\text { Stek pucuk bagian atas } \\
\text { (Uppershoot cuttings) }\end{array}$ & $\begin{array}{l}\text { Stek pucuk bagian bawah } \\
\text { (Down shoot cuttings) }\end{array}$ \\
\hline Tanah+pasir $($ Soil+sand, 2:1, v/v) & $11,14 \mathrm{a}$ & $7,61 \mathrm{~b}$ \\
\hline $\begin{array}{l}\text { Sebuk sabut kelapa+ sekam (Cocopet }+ \text { husk) }(2: 1 \text {, } \\
\text { v/v) }\end{array}$ & $5,06 \mathrm{c}$ & $3,84 \mathrm{c}$ \\
\hline Pasir (Sand) & $4,13 \mathrm{c}$ & $6,25 \mathrm{c}$ \\
\hline
\end{tabular}

Keterangan (Remark): Angka yang diikuti dengan huruf yang sama pada kolom yang sama tidak berbeda nyata pada taraf uji 5\% (DMRT) (Values in rows followed by the same letter in the same column are not significantly different at level of $5 \%$ base on Duncan Multiple Range Test)

Media tanah+pasir (2:1, v/v) dan media pasir memiliki kerapatan lindak terbesar. Kedua media tersebut memiliki drainase cukup tinggi, sehingga jumlah air tersedia cukup rendah dibandingkan media serbuk sabut kepala+sekam (2:1, 


\section{Penggunaan Media, Bahan Stek, dan Zat Pengatur Tumbuh Terhadap Keberhasilan Stek Masoyi (Cryptocarya massoy (Oken) Kosterm)}

Darwo dan Irma Yeny

v/v). Namun demikian, media serbuk sabut kepala+sekam tersebut memiliki kadar air pada titik layu cenderung rendah dibandingkan media lainnya. Media tanah+pasir $(2: 1, \mathrm{v} / \mathrm{v})$ memiliki porositas yang lebih tinggi daripada serbuk sabut kelapa+sekam $(2: 1, \mathrm{v} / \mathrm{v})$, namun lebih rendah daripada media pasir. Media tanah+pasir $(2: 1$, v/v) memiliki ketersediaan air lebih tinggi daripada media pasir, namun lebih rendah daripada media serbuk sabut kelapa+sekam $(2: 1$, $\mathrm{v} / \mathrm{v})$. Media tanah+pasir (2:1, v/v) memiliki kadar air pada titik layu permanen relatif lebih rendah daripada media pasir, tetapi lebih tinggi dibandingkan dengan media serbuk sabut kelapa+sekam $(2 ; 1, \mathrm{v} / \mathrm{v})$.

\section{Pengaruh media terhadap penampakan dan perakaran stek}

Gambar 1 menunjukkan pengaruh media terhadap kondisi/penampakan stek pucuk masoyi secara umum (bagian pucuk atas dan pucuk bawah berada dalam pottray yang sama). Pada umur 8 minggu mulai tampak perubahan kondisi: (1) stek pada media tanah+pasir $(2: 1, \mathrm{v} / \mathrm{v})$ memiliki daun hijau dengan jumlah daun lebih banyak, (2) stek pada media serbuk sabut kelapa+sekam $(2: 1$, v/v) memiliki daun sedikit menguning dengan jumlah daun lebih sedikit, dan (3) stek pada media pasir memiliki daun berwarna hijau namun jumlah daunnya paling rendah.

Tabel (Table 4). Sifat fisik media perakaran stek C. massoy (The physical characteristic of rooting media for shoot cuttings of $\underline{\mathrm{C}}$. massoy)

\begin{tabular}{|c|c|c|c|}
\hline \multirow[b]{2}{*}{$\begin{array}{l}\text { Sifat fisik media stek (The physical characteristic of } \\
\text { cuttings) }\end{array}$} & \multicolumn{3}{|c|}{ Media stek (Cutting medias) } \\
\hline & $\begin{array}{l}\text { Tanah+pasir } \\
(\text { Soil +sand) } \\
(2: 1, \mathrm{v} / \mathrm{v})\end{array}$ & $\begin{array}{c}\text { Serbuk sabut } \\
\text { kelapa+ sekam } \\
(\text { Cocopeat }+ \text { husk }) \\
(2: 1, \mathrm{v} / \mathrm{v})\end{array}$ & Pasir (Sand) \\
\hline Kerapatan lindak (Bulk density) (g/cc) & 1,21 & 0,76 & 1,19 \\
\hline Kesarangan ruang pori total (Porosity) (\%) & 54,34 & 53,94 & 55,09 \\
\hline $\begin{array}{l}\text { Kadar air pada kapasitas lapang pada } \mathrm{pF} 2,54 \% \\
\text { (Moisture content at field capacity at pF } 2.54 \% \text { ) (\%) }\end{array}$ & 46,76 & 45,95 & 47,26 \\
\hline $\begin{array}{l}\text { Kadar air pada titik layu permanen pada } \mathrm{pF} 4,20 \% \\
\text { (Moisture content at permanent wilting point at pF } \\
4.20 \%)(\%)\end{array}$ & 34,21 & 24,30 & 38,71 \\
\hline $\begin{array}{l}\text { Kadar air pada } \mathrm{pF} 1,00 \% \text { (Moisture content at } \mathrm{pF} \\
1.00 \%)(\%)\end{array}$ & 52,43 & 53,56 & 52,64 \\
\hline Pori drainase cepat (Drainage pore fast) $(\%)$ & 3,76 & 0,84 & 6,71 \\
\hline Jumlah air tersedia (Available water capacity) (\%) & 12,57 & 21,65 & 8,55 \\
\hline
\end{tabular}
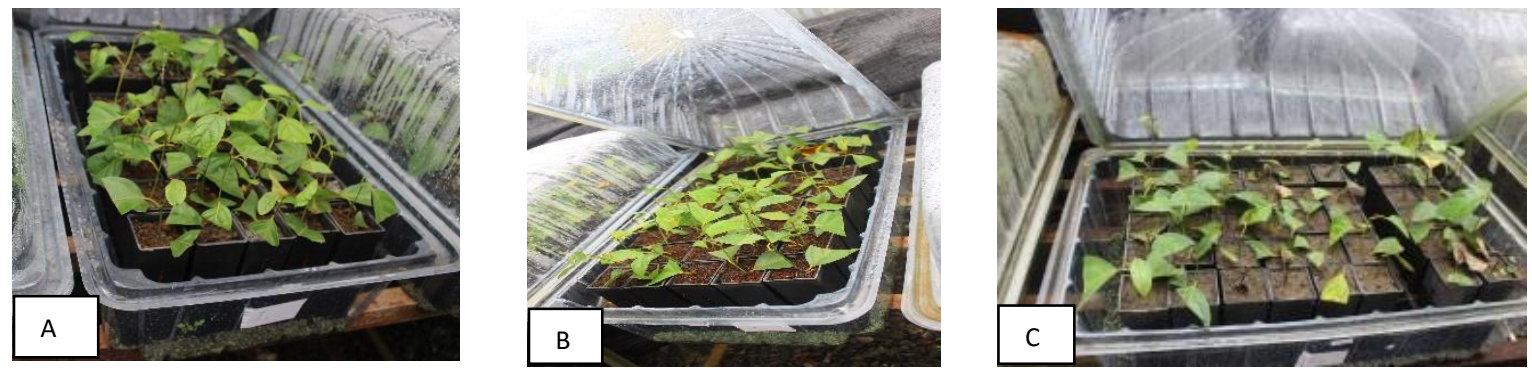

Keterangan (Remarks): A = Tanah+pasir (Soil+sand, 2:1, v/v), B = Serbuk sabut kepala+sekam (Cocopet + husk, 2:1, v/v), dan $\mathrm{C}=$ Pasir (Sand)

Gambar (Figure) 1. Stek $C$. massoy pada umur 8 minggu pada tiga media perakaran (Cutting materials of $\underline{\mathrm{C}}$. massoy at 8 weeks old on three rooting medias) 

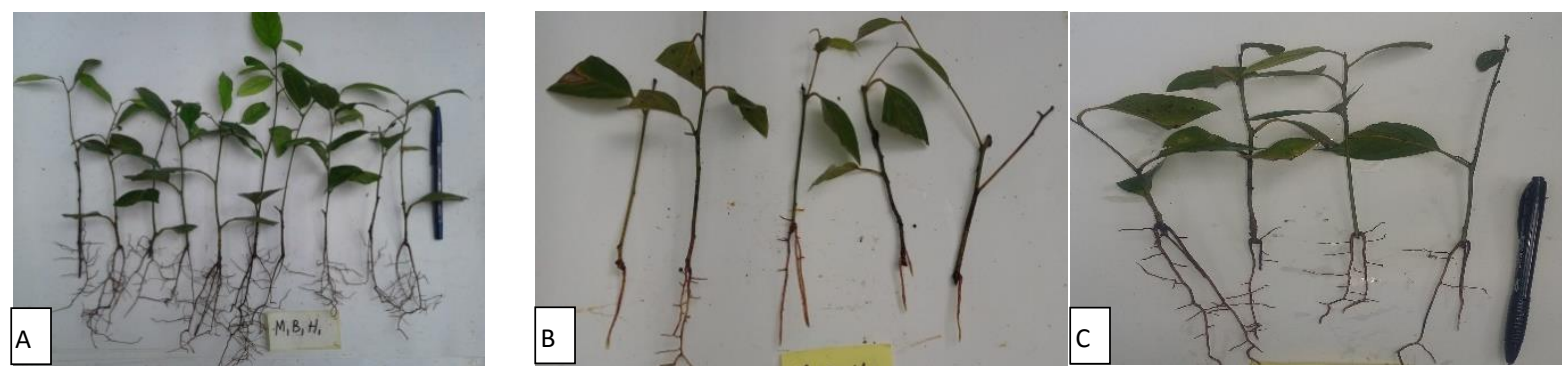

Keterangan (Remarks): A = Tanah+pasir (Soil+sand, 2:1, v/v), B = Serbuk sabut kepala+sekam (Cocopet+husk, 2:1, v/v), C = Pasir (Sand)

Gambar (Figure) 2. Perakaran stek pucuk bagian atas dan bagian bawah $C$. massoy pada umur 16 minggu (Rooting of the upper shoot cuttings and thedown shoot cuttings of $\underline{\mathrm{C}}$. massoy at 16 weeks old)

Tabel 2 menunjukkan stek pucuk bagian atas dan stek pucuk bagian bawah tidak berbeda nyata pada parameter panjang akar, jumlah akar dan jumlah daun. Namun Gambar 2 menunjukkan bahwa pengelompokkan bahan stek berdasarkan perbedaan media menunjukkan media tanah+pasir $(2: 1, \mathrm{v} / \mathrm{v})$ memiliki persen berakar, panjang akar, jumlah akar dan jumlah daun baru terbanyak dibandingkan kedua media lainnya.

\section{B. Pembahasan}

Stek pucuk masoyi telah diujikan jenis media tumbuh, sumber stek dan jenis hormon yang digunakan dengan parameter yang dilihat adalah persen berakar stek, panjang akar stek, jumlah akar dan jumlah daun. Pasetriyani (2014) menyatakan bahwa pertumbuhan stek pucuk dipengaruhi oleh faktor media tumbuh, jenis stek, posisi stek pada tanaman induk, dan lain-lain. Jenis media tumbuh yang tepat untuk pertumbuhan stek pucuk menjadi perhatian, seperti media tumbuh yang porus agar proses aerasi dan drainase bisa berjalan dengan baik, memiliki daya ikat air yang baik dan bebas patogen (Adinugraha, 2011). Karakteristik media tersebut bisa memengaruhi kemampuan perakaran stek pucuk. Terbentuknya akar pada stek merupakan faktor penting karena akar dapat menyerap unsur hara dari dalam tanah dan dapat mendukung kelangsungan hidupnya (Mashudi \& Adinugraha,
2015). Pada fase pertumbuhan stek setelah pertumbuhan akar yaitu keberadaan daun pada stek. Adanya daun dapat menghasilkan persen jadi stek pucuk, jumlah akar, dan panjang akar lebih baik (Akinyele, 2010). Semakin luas permukaan daun, maka fotosintat yang dihasilkan cenderung semakin banyak (Mashudi \& Adinugraha, 2015). Keberadaan daun sangat penting terhadap keberhasilan stek pucuk. Luas daun yang disisakan pada stek pucuk harus diperhatikan, sebab apabila daun pada stek terlalu banyak (luas), maka laju transpirasi akan tinggi, sehingga akan menyebabkan stek menjadi layu. Terkait dengan hal tersebut, maka pada penelitian ini daun pada stek pucuk bagian atas dan stek pucuk bagian bawah disisakan 2-3 helai dan setiap helai dipotong separuhnya, sehingga tidak terdapat perbedaan keberadaan jumlah daun dan luas daun pada perlakuan awal. Aspek lainnya yang menjadi faktor keberhasilan stek pucuk adalah sumber stek yang diambil. Bagian stek pucuk masoyi yang diujikan berupa stek pucuk bagian atas dan stek pucuk bagian bawah. Pengujian ini diharapkan bisa mengoptimalkan bagian stek pucuk yang masih bisa digunakan. Selanjutnya yang dianalisis pengaruh pemberian hormon zat pengatur tumbuh terhadap keberhasilan stek pucuk masoyi. 


\section{Pengaruh media tumbuh stek}

Sifat fisik media memberikan respon yang berbeda pada keberhasilan stek masoyi. Penggunaan media tanah+ pasir $(2: 1, \mathrm{v} / \mathrm{v})$ telah menghasilkan nilai tertinggi pada semua parameter yaitu persen berakar $71,67 \%$, panjang akar 9,30 $\mathrm{cm}$, jumlah akar 2,14 helai, dan jumlah daun 1,99 helai. Hal ini dikarenakan media tanah+pasir $(2 ; 1, \mathrm{v} / \mathrm{v})$ memiliki kemampuan dalam memenuhi ketersediaan air serta menjaga suhu dan kelembaban, sehingga semua parameter yang diamati menunjukkan respon positif. Respon yang berbeda terjadi pada stek kilemo (Litsea cubeba (Lour.) Pers.) yang satu famili dengan masoyi yaitu famili Laureaceae. Pada stek kilemo, media pasir memiliki persen berakar tertinggi $(15,6 \%)$ dibandingkan dengan media campuran serbuk sabut kelapa+sekam $(2: 1$, v/v) maupun media campuran serbuk sabut kelapa+arang sekam (2:1, v/v) (Putri, \& Danu, 2014). Uji media pada stek pucuk damar (Agathis laranthifolia Salisb.) menghasilkan media campuran serbuk sabut kelapa+ sekam (2:1) sebagai media terbaik untuk perakaran stek damar dengan hasil persen berakar stek damar 67\% (Danu et al., 2011). Sementara itu uji media dan pemberian zat pengatur pada stek ganitri (Elaeocarpus ganitrus Roxb) menunjukkan media pasir dan pemberian IAA 300 ppm menghasilkan persen hidup, jumlah tunas, jumlah akar, panjang akar, berat kering akar, dan berat kering tunas yang lebih tinggi (Rachman \& Rohandi, 2012).

Media tanah+pasir $(2: 1, \mathrm{v} / \mathrm{v})$ dalam penelitian ini memiliki kerapatan lindak porositas dan jumlah air tersedia yang sedang (tidak terlalu padat, tidak terlalu poros, dan jumlah air tersedia cukup) dibandingkan dengan media serbuk sabut kelapa+sekam $(2: 1, \mathrm{v} / \mathrm{v})$ dan media pasir. Nilai kerapatan lindak 1,21 g/cc, porositas $54,34 \%$, dan jumlah air tersedia $12,57 \%$ menunjukkan kondisi media tanam yang sangat mendukung proses pembentukan akar pada stek masoyi. Perbedaan fisik media terlihat pula pada kondisi stek masoyi baik stek pucuk bagian atas maupun stek pucuk bagian bawah. Media tanah+pasir (2:1, v/v) menghasilkan stek sampai akhir pengamatan tampak segar dan menghasilkan daun muda yang banyak. Media serbuk sabut kelapa+sekam $(2: 1, \mathrm{v} / \mathrm{v})$ sampai umur 2 bulan masih segar, namun setelah itu mulai menguning. Pada bulan ketiga stek menguning dan membusuk. Berbeda dengan media pasir dimana sampai akhir pengamatan tetap segar, walaupun jumlah tunas dan daun yang dihasilkan relatif lebih sedikit dibandingkan media tanah+ pasir $(2: 1, \mathrm{v} / \mathrm{v})$.

Berdasarkan perbedaan beberapa media stek, maka stek masoyi menghasilkan persen berakar yang rendah pada media yang mengandung kadar air yang tinggi. Kondisi ini diduga akibat tingginya kadar air pada kapasitas lapang dan titik layu permanen. Ketersediaan air yang cukup tinggi pada media tersebut mengakibatkan stek membusuk. Subiakto (2009) menyatakan bahwa serbuk sabut kelapa bersifat seperti spons yang banyak menyerap air dan mempertahankan air, sehingga dapat mempertahankan kelembaban medium. Media stek tanaman masoyi lebih menyukai media dengan nilai kisaran ketersediaan air pada kapasitas lapang 46,78\% dan titik layu permanen $34,21 \%$. Stek masoyi berbeda dengan tanaman kayu bawang, dimana media terbaiknya serbuk sabut kelapa+ sekam (2:1, v/v) dengan IBA 50 ppm dapat menghasilkan persen berakar sebesar 95\% dengan jumlah akar 2 buah dan jumlah daun 2 helai. Media tersebut memiliki ketersediaan air pada kapasitas lapang mencapai $80,95 \%$ dan ketersediaan air pada titik layu permanen 58,56\% (Danu, \& Kurniati, 2014). Begitu juga media stek serbuk sabut kelapa+ sekam telah memberikan pengaruh yang baik terhadap keberhasilan stek pucuk 
tembesu (Fagraea fragrans Roxb.) (Istomo et al., 2014). Oleh karena itu, tidak selalu media tanam yang menghasilkan persen berakar yang terbaik dapat digunakan sebagai media tanam untuk stek jenis lainnya.

Terdapat interaksi sangat nyata antara media dan bagian stek pucuk tanaman masoyi, yaitu pada parameter panjang akar. Pada parameter panjang akar, media tanah+pasir $(2: 1, \mathrm{v} / \mathrm{v})$ dan bagian atas pucuk memberikan hasil yang terbaik dibandingkan media serbuk sabut kelapa+sekam $(2: 1, \mathrm{v} / \mathrm{v})$ dan media pasir. Hal ini dikarenakan media tanah+pasir mampu menyerap air, namun tidak terlalu lama untuk mempertahankan air, sehingga media tidak basah dalam waktu yang lama. Kadar air pada kapasitas lapang 46,78\% dan kadar air pada titik layu permanen $34,21 \%$ merupakan kemampuan media tanam yang cocok bagi pertumbuhan stek pucuk masoyi. Selain itu media tanah+pasir (2:1, v/v) yang digunakan diduga mengandung/ unsur hara yang mendukung pertumbuhan panjang akar.

Menurut Minarningsih, Yeny, Santoso, \& Purwanto (2017) bahwa media tanah+pasir $(2: 1, \mathrm{v} / \mathrm{v})$ mengandung unsur hara $\mathrm{N}$ total $0,22 \%$ (sedang). Nilai ini lebih rendah jika dibandingkan media serbuk sabut kelapa+sekam (2:1, v/v) yaitu $\mathrm{N}$ total $1,08 \%$ (sangat tinggi). Namun demikian, panjang akar tertinggi ditunjukkan oleh media tanah+pasir (2:1, $\mathrm{v} / \mathrm{v})$ sebesar $9,3 \mathrm{~cm}$ dan media serbuk sabut kelapa+sekam (2:1, v/v) sebesar $4,46 \mathrm{~cm}$. Kondisi ini membuktikan proses perpanjangan akar ditentukan oleh ketersediaan hara pada media tanam. Selain ditentukan oleh faktor genetik, morfologi akar ditentukan pula oleh keadaan lingkungan media, yaitu hara. Apabila hara tersedia dalam jumlah yang cukup, maka tanaman akan membentuk sistem akar yang dangkal. Sebaliknya, tanaman dengan perlakuan media tanam yang minim hara cenderung memperluas akar untuk mendapatkan hara (Rianto, Suwandi, \& Sulistiyono, 2016).

Pada kondisi ini jumlah unsur hara pada media media tanah+pasir $(2: 1, \mathrm{v} / \mathrm{v})$ yang memiliki $\mathrm{N}$-total pada kategori sedang dianggap minim untuk untuk mendukung pertumbuhan organ tanaman akar masoyi, sehingga memiliki sistem perakaran yang luas dibandingkan media lainnya. Selanjutnya untuk menghasilkan stek dengan daya perakaran tinggi dibutuhkan perkembangan akar, batang dan daun yang akan meningkatkan laju fotosintesis, sehingga menghasilkan bahan makanan (fotosintat) yang tinggi bagi kebutuhan tanaman (Supriyanto \& Prakasa, 2011; Winarni, 2009).

\section{Pengaruh bahan stek}

Perbedaan bahan stek menunjukkan bahwa stek pucuk bagian atas memiliki kemampuan untuk menghasilkan pucuk daun baru lebih cepat dibandingkan stek pucuk bagian bawah. Namun demikian, secara statistik jumlah daun yang dihasilkan tidak berbeda antara stek pucuk bagian atas dan bagian bawah. Oleh karena itu, anakan masoyi umur 1 tahun berpotensi sebagai bahan stek mulai dari pucuk sampai dengan 6 nodul pertama setelah bagian pucuk. Hal ini disebabkan karena anakan masoyi umur 1 tahun merupakan bahan stek yang masih juvenil (muda secara fisiologis) dan asal bahan stek yang tergolong semai juvenil. Bagian ini memiliki kemampuan berakar yang lebih baik daripada bahan stek yang lebih tua (Putri, \& Siregar, 2016). Seperti bahan stek dari bibit (semai juvenil) pada tanaman tembesu (F. fragrans) memberikan persen berakar lebih baik dibandingkan asal bahan stek trubusan maupun pucuk pohon tua (Istomo, Subiakto, \& Ragmadianto, 2014). Hal ini disebabkan bibit memiliki kemampuan untuk melakukan perpanjangan sel (elongation) yang sangat pesat atau disebut juga fase juvenil. 
Stek pucuk bagian bawah memiliki diameter batang lebih besar daripada bagian pucuk atas sehingga keberhasilan kemampuan tumbuh dari stek pucuk bagian bawah lebih rendah daripada bagian pucuk atas. Hal ini sesuai dengan hasil penelitian Pramono \& Siregar (2016) yang menyatakan bahwa semakin besar diameter pangkal stek semakin rendah persen hidup dan semakin sedikit jumlah daun serta semakin pendek akar yang terbentuk. Namun demikian, stek pucuk bagian bawah masih dapat digunakan sebagai bahan stek dengan nilai persen berakar yang cukup tinggi $(42,22 \%)$, sehingga penggunaan tanaman masoyi umur 1 tahun sebagai bahan stek dapat digunakan sampai 6 nodul teratas.

\section{Pengaruh zat pengatur tumbuh}

Pemberian dosis NAA 500 ppm dan $1.000 \mathrm{ppm}$ menghasilkan persen berakar yang tidak berbeda nyata dengan kontrol. Kondisi ini menunjukkan bahwa sumber stek dari bibit berumur 1 tahun berada pada fase juvenil dan mampu melakukan perpanjangan sel. Perpanjangan sel yang terjadi pada stek masoyi diduga dipengaruhi oleh hormon endogen dan ketersediaan air. Ahkami et al. (2013) menyebutkan ketersediaan air mampu menyebabkan pengenduran dinding sel sehingga mampu mendesak pembesaran sel dan pembentukan pembentukan akar .

Analisis distribusi zat pengatur tumbuh IAA dalam stek mengungkapkan bahwa sekitar $40 \%$ dan $10 \%$ dari total IAA terdapat pada daun dan zona pangkal batang sebagai tempat terjadinya perakaran (Ahkami et al., 2013). Apabila zat pengatur tumbuh (ZPT) endogen berada di bawah optimal, maka pemberian ZPT eksogen diperlukan untuk menghasilkan respon yang maksimal. Pada tanaman dimana ZPT endogen dibawah optimal, pemberian ZPT eksogen pada proses stek diperlukan agar diperoleh kualitas bibit yang baik dan mengurangi jumlah bibit yang tumbuh abnormal (Leovici, Kastono, \& Putra, 2014). Seperti pada stek Macleania rupestris dengan menggunakan IBA atau NAA $500 \mathrm{mg}$ menghasilkan jumlah akar tertinggi (Veloza et al., 2014).

Perbanyakan stek masoyi dengan aplikasi media, bahan stek dan dosis zat pengatur tumbuh NAA pada sistem KOFFCO menunjukkan bahwa media tanah+pasir $(2: 1$. v/v) memiliki persen berakar, panjang akar dan jumlah daun tertinggi $(71,67 \% ; 9,3 \mathrm{~cm}$; dan 2 daun) sedangkan pada parameter jumlah akar ketiga media tidak berbeda. Asal bahan stek yang memiliki persen berakar paling tinggi adalah stek pucuk bagian atas $(53,33 \%)$ dibandingkan dengan stek pucuk bagian bawah (42,22\%). Pemberian dosis NAA 500 ppm dan 1.000 ppm pada semua parameter yaitu persen berakar, panjang akar, jumlah akar dan jumlah daun menunjukkan tidak berbeda dengan kontrol. Pada stek pucuk masoyi tidak memerlukan tambahan zat pengatur tumbuh, tetapi diperlukan media tumbuh tanah+pasir $(2: 1, \mathrm{v} / \mathrm{v})$.

\section{KESIMPULAN DAN SARAN}

\section{A. Kesimpulan}

Penyiapan bibit masoyi dengan stek merupakan salah satu upaya menyediakan bibit masoyi dalam jumlah yang cukup dan tersedia tepat waktu. Uji media, bahan stek, dan penggunaan zat pengatur tumbuh NAA menunjukkan bahwa faktor media memengaruhi secara signifikan terhadap persen berakar, panjang akar, dan jumlah daun stek masoyi. Media tanah+pasir $(2: 1, \mathrm{v} / \mathrm{v})$ merupakan media yang terbaik bagi pertumbuhan stek masoyi dan menghasilkan panjang akar yang tertinggi tanpa perlu diberikan zat pengatur tumbuh NAA. Bagian stek pucuk atas lebih baik daripada bagian stek pucuk bawah, namun stek pucuk bagian bawah masih dapat digunakan 
sebagai bahan stek dengan nilai persen berakar yang cukup tinggi $(42,22 \%)$ sehingga penggunaan tanaman masoyi umur 1 tahun sebagai bahan stek dapat digunakan sampai 6 nodul teratas.

\section{B. Saran}

Perbanyakan tanaman masoyi secara vegetatif dapat dilakukan dengan sistem stek pada media tanah+pasir (2:1, v/v) tanpa perlu penambahan hormon tumbuh NAA. Uji kualitas mutu fisik bibit asal stek serta ketersediaan auksin alami pada stek masoyi perlu dianalisis lebih lanjut guna meningkatkan efektifitas per-banyakan tanaman masoyi meng-gunakan stek.

\section{UCAPAN TERIMA KASIH}

Penelitian ini dibiayai DIPA APBN Pusat Penelitian dan Pengembangan Hutan tahun anggaran 2016. Terima kasih disampaikan kepada Bapak Ir. Atok Subiakto, M.Sc. yang telah memberikan izin penggunaan rumah kaca dan peralatannya, serta Dr. Hani Sitti Nuroniah atas arahannya. Ucapan terima kasih juga disampaikan pada Bapak Abdurahman Syakur, Kusman, Nana, Tomi, Wahyu, Ibu Yetti Heryati, Minarningsih, Endang, dan Reni atas bantuannya selama penelitian berlangsung.

\section{DAFTAR PUSTAKA}

Adinugraha, H. (2011). Pengaruh umur pohon induk, umur tunas dan jenis media terhadap pertumbuhan stek sukun. Jurnal Penelitian Hutan Tanaman, 5(1), 23-30.

Ahkami, M. H., Melzer, M., Ghaffari, M., Pollmann, S., Javid, M., Shahinnia, F., \& Hajirezae, M. R. (2013). Distribution of indole-3- acetic acid in Petunia hybrida shoot tip cuttings and relationship between auxin transport, carbohydrate metabolism and adventitious root formation. Jurnal Planta, 283, 499517. http://doi.org/10.1007/s00425013-1907-z

Akinyele, A. (2010). Effects of growth hormones, rooting media and leaf size on juvenile stem cuttings of Buchholzia coriacea Engler. Annals of Forest Research, 53(2), 127-133. Danu, \& Kurniati, P. (2014). Pengaruh sifat fisik media dan zat pengatur tumbuh IBA pada pertumbuhan stek kayu bawang (Azadirachta exelsa L. Jurnal Perbenihan Tanaman Hutan 2(2); 8998.

Badan Standarisasi Nasional. (2013). Kulit Masohi.

Danu, Subiakto, A., \& Putri, K. P. (2011). Uji stek pucuk damar (Agathis loranthifolia Salisb.) pada berbagai media dan zat pengatur tumbuh. Jurnal Penelitian Hutan dan Konservasi Alam, 8(3), 245-252.

Istomo, Subiakto, A., \& Ragmadianto, S. (2014). Pengaruh asal bahan dan media stek terhadap keberhasilan stek pucuk tembesu. Jurnal Berita Biologi, 13(3), 275-281.

Leovici, H., Kastono, D., \& Putra, E. T. (2014). Pengaruh macam dan konsentrasi bahan organik sumber zat pengatur tumbuh alami terhadap pertumbuhan awal tebu (Saccharum officinarum L.). Vegetalika, 3(1), 2234.

Mashudi, \& Adinugraha, H. (2015). Kemampuan tumbuh stek pucuk pulai gading (Alstonia scholaris (L.) R. Br.) dari beberapa posisi bahan stek dan model pemotongan stek. Jurnal Penelitian Kehutanan Wallacea, 4(1), 63-69. 
Minarningsih, Yeny, I., Santoso, \& Purwanto, B. (2017). Kesesuaian media sapih terhadap pertubuhan bibit masoyi (Cryptocarya massoy (Oken) Kosterm) di persemaian. Dalam Seminar Nasional Silvikultur. Banjar Baru.

Pasetriyani, E. (2014). Pengaruh macam media tanam dan zat pengatur tumbuh growtone terhadap pertumbuhan stek batang tanaman jarak pagar (Jatropa curcas Linn. Jurnal Agrosci, 7, 82-88.

Pramono, A.A., \& Siregar, N. (2016). Pengaruh diameter pucuk dan dosis iba terhadap perakaran stek benuang (Octomeles sumatrana Miq). In Prosiding seminar nasional silvikultur III. IPB International convention center (pp. 69-73). Bogor 19-20 April 2015

Putri, K., \& Danu. (2014). Uji stek kilemo (Litsea cubeba L. Persoon) pada berbagai media perakaran dan zat pengatur tumbuh. Jurnal Forest Rehabilitation, 2(2), 89-97.

Putri, K., \& Siregar, N. (2016). Pengaruh bahan stek dan zat pengatur tumbuh terhadap keberhasilan stek pucuk Malapari (Pongamia pinnata). Jurnal Perbenihan Tanaman Hutan 4(1):1-8

Rachman, E., \& Rohandi, A. (2012). Keberhasilan stek pucuk ganitri (Elaeocarpus ganitrus Roxb) pada aplikasi antara media tanam dan hormon tumbuh. Jurnal Penelitian Hutan Tanaman, 9(4), 219-225.

Rianto, M., Suwandi, \& Sulistiyono, A. (2016). Pengaruh panjang stek dan media tanam terhadap pertumbuhan bibit buah naga (Hylocereus sp.). Plumula, 5(2), 113-124.

Rostiwati, T., \& Efendi, R. (2013). Mendulang uang tanpa tebang, Lima jenis HHBK unggulan. (G. Pari \& P. Setio, Eds.). Bogor: Forda Press.

Subiakto, A. (2009). Aplikasi Koffco untuk produksi stek jenis pohon indigenous. Bogor: Pusat Litbang Hutan dan Konservasi Alam.

Suminar, S., Arifin, B., \& Kemala, T. (2015). Naskah akademik membangun standar nasional Indonesia untuk komoditas minyak masoyi.

Supriyanto \& Prakasa, K. (2011). Pengaruh zat pengatur tumbuh rootone-F terhadap pertumbuhan stek Duabanga mollucana Blume. Jurnal Silvikultur Tropika,3(1), 59-65.

Veloza, C., Durán, S., Magnitskiy, S., \& Lancheros, H. (2014). ) Rooting ability of stem cutting of Macleania rupestris Kunth A.C.Sm a South American fruit species. International Journal of Fruit Science, 14(4), 343361. International Journal of Fruit Science, 14(4), 343-361. 